Original article - Laboratory Science

\title{
Reduced expression of Apolipoprotein E and I mmunoglobulin heavy constant gamma 1 proteins in Fuchs' endothelial corneal dystrophy
}

\author{
Abraham Kuot PhD, ${ }^{1 *}$ Maurizio Ronci PhD, ${ }^{2 *}$ Richard Mills FRANZCO, ${ }^{1}$ Sonja Klebe \\ FRCPA, ${ }^{3}$ Grant Snibson FRANZCO, ${ }^{4}$ Steven Wiffen FRANZCO, ${ }^{5}$ Raymond Loh \\ FRANZCO, ${ }^{1}$ Mark Corbett PhD, ${ }^{6}$ Tim Chataway PhD, ${ }^{7}$ Kathryn P Burdon PhD, ${ }^{1,8}$ J amie \\ E. Craig FRANZCO, ${ }^{1}$ Andrea Urbani $\mathrm{PhD}^{9,10}$ and Shiwani Sharma $\mathrm{PhD}^{1}$
}

${ }^{1}$ Department of Ophthalmology, Flinders University, Bedford Park, SA 5042, Australia ${ }^{2}$ Department of Medical, Oral and Biotechnological Sciences, University of G.d'Annunzio Chieti Pescara, Italy

${ }^{3}$ Department of Anatomical Pathology, Flinders University, Bedford Park, SA 5042, Australia

${ }^{4}$ Centre for Eye Research Australia, Royal Victorian Eye and Ear Hospital, East Melbourne, VIC 3002, Australia

${ }^{5}$ The Lions Eye Bank of Western Australia, Lions Eye Institute, Nedlands, WA 6009, Australia

${ }^{6}$ Discipline of Paediatrics, School of Medicine and Robinson Research Institute, University of Adelaide, Adelaide, SA 5005, Australia

${ }^{7}$ Department of Human Physiology, Proteomics Laboratory, Flinders University, Bedford Park, SA 5042, Australia

${ }^{8}$ Menzies Institute for Medical Research, University of Tasmania, Hobart, TAS, 7000 Australia

${ }^{9}$ Institute of Biochemistry and Clinical Biochemistry, Università Cattolica del Sacro Cuore, Rome, Italy

This is the author manuscript accepted for publication and has undergone full peer review but has not been through the copyediting, typesetting, pagination and proofreading process, which may lead to differences between this version and the Version of Record. Please cite this article as doi: 10.1111/ceo.13569

This article is protected by copyright. All rights reserved. 
${ }^{10}$ Department of Laboratory Diagnostic and Infectious Diseases, Fondazione Policlinico Universitario Agostino Gemelli-IRCCS, Rome, Italy

*contributed equally to this work

Correspondence: Shiwani Sharma, GPO Box 2100, Adelaide, SA 5001, Australia Email: Shiwani.sharma@flinders.edu.au

Short running title: Descemet's' membrane proteomics in Fuchs' Received 1 J anuary 2019; accepted 5 J une 2019

Funding sources / Financial disclosure: This work was funded by the Ophthalmic Research Institute of Australia and the Flinders Foundation, Adelaide, Australia. KPB and JEC are recipients of the National Health and Medical Research Council (Australia) Senior Research and Practitioner Fellowships, respectively. Conflict of interest: None 


\section{ABSTRACT}

Background: Fuchs' endothelial corneal dystrophy (FECD) is a progressive and potentially a sight threatening disease, and a common indication for corneal grafting in the elderly. Aberrant thickening of Descemet's membrane, formation of microscopic excrescences (guttae) and gradual loss of corneal endothelial cells are the hallmarks of the disease. The aim of this study was to identify differentially abundant proteins between FECD-affected and unaffected Descemet's membrane.

Methods: Label-free quantitative proteomics using nUPLC-MS ${ }^{\mathrm{E}}$ (nanoscale ultraperformance liquid chromatography-mass spectrometry) was employed on affected and unaffected Descemet's membrane extracts, and interesting findings were further investigated using quantitative reverse transcription-polymerase chain reaction and immunohistochemical techniques.

Results: Quantitative proteomics revealed significantly lower abundance of Apolipoprotein E (APOE) and Immunoglobulin heavy constant gamma 1 protein (IGHG1) in affected Descemet's membrane. The difference in the distribution of APOE between affected and unaffected Descemet's membrane and of IGHGI detected by immunohistochemistry support their down-regulation in the disease. Comparative gene expression analysis showed significantly lower APOE mRNA levels in FECD-affected than unaffected corneal endothelium. IGHG1 gene is expressed at extremely low levels in the corneal endothelium, precluding relative expression analysis.

Conclusions: This is the first study to report comparative proteomics of Descemet's membrane tissue, and implicates dysregulation of APOE and IGHGI proteins in the pathogenesis of Fuchs endothelial corneal dystrophy.

Key words: Fuchs' Endothelial dystrophy, proteomics, Apolipoproteins E, Immunoglobulin heavy constant gamma 1 protein, real-time polymerase chain 
reaction

This article is protected by copyright. All rights reserved. 


\section{I NTRODUCTION}

Fuchs' endothelial corneal dystrophy (FECD, OMIM 136800) is a progressive degenerative disease of the corneal endothelium $(C E)^{1}$ that can lead to blindness. The presence of posterior protrusions (guttae) in Descemet's membrane (DM) ${ }^{1}$, the collagen-rich basement membrane of the endothelium ${ }^{1}$, is the earliest clinical feature of the disease. Progression of the disease is accompanied by abnormal thickening of DM, and change in corneal endothelial cell (CEC) size and shape and gradual reduction in numbers ${ }^{2}$. Loss of endothelial cells ${ }^{2}$ impairs CE pump function resulting in corneal oedema and in turn to pain and, if not treated, vision loss. Corneal transplantation is the only effective treatment for severe disease ${ }^{3}$.

FECD rarely occurs as an early onset, and more commonly as a late onset disease. Early onset can be in the first to fourth decade of life; manifestation after the fourth decade of life is considered late-onset. The prevalence of late-onset FECD varies markedly across the world. The disease affects approximately $4 \%$ of the population over the age of 40 years in the USA ${ }^{4}$ but is less frequent in Asian ${ }^{5}$ and MiddleEastern $^{6}$ populations. In Australia, corneal grafting for FECD accounts for approximately $26 \%$ of all corneal grafts performed annually ${ }^{7}$ indicating its relatively common prevalence in older adults.

FECD is a genetically heterogeneous disease with poorly understood disease mechanism. The contributing genetic factors identified to date account for a small proportion of cases $^{8-10}$. Mutations in COLBA2 gene have been found in patients with early-onset disease and in TCF8, SLC4A11, LOXHD1 and AGBL1 genes in those with late-onset disease ${ }^{11,12}$. In addition, nucleotide variants at TCF4, KANK4, LAMCI and LINC00970/ATP1B1 loci and an intronic trinucleotide repeat expansion in TCF4 gene have been associated with significantly increased risk of late-onset disease ${ }^{13}{ }^{14}$. The 
molecular studies reported to date suggest the involvement of cellular stress due to redox imbalance and unfolded protein response, mitochondrial DNA damage, and cell death by apoptosis and autophagy, in the disease ${ }^{15-19}$. However the pathophysiology remains poorly understood. Elevated Clusterin (CLU) and Transforming growth factor, $\beta$-induced (TGFBI) gene expression in CE, and higher abundance of the encoded proteins in DM have been reported in affected compared to unaffected corneas ${ }^{20}$. Clusterin is a molecular chaperone and a stress response protein with both intracellular and extracellular functions ${ }^{21}$. TGFBI is an extracellular protein involved in regulation of cell adhesion ${ }^{20,22}$. Up-regulation of these genes/ proteins in FECD indicates their roles in abnormal thickening of DM and/or corneal endothelial decompensation in the disease. Hence knowledge of dysregulated genes/proteins can shed light on the molecular mechanisms underlying pathophysiology of the disease. In this study, we aimed to identify differentially abundant proteins between FECD-affected and unaffected DM to gain further insight into pathophysiology of the disease. We employed label-free quantitative mass spectrometry, and report identification of novel differentially abundant proteins in the DM in this disease.

\section{METHODS}

\subsection{Collection of surgical specimens}

The research was approved by the Southern Adelaide Clinical Human Research Ethics Committee, Southern Adelaide Local Health Network and Flinders University, and Human Research Ethics Committee, Royal Victorian Eye and Ear Hospital. Surgical corneal endothelium-Descemet's membrane complex (CE-DM) specimens were obtained from patients undergoing Descemet's stripping automated endothelial keratoplasty (DSAEK) for advanced FECD (Grades $3-6)^{23}$; the disease was graded from 0 - 6 according to a modified Krachmer grading system ${ }^{24}$. Equivalent 
specimens dissected from normal cadaveric corneas without a medical history of FECD obtained through the Eye Bank of South Australia, were used as controls. All the specimens were from Caucasian Australians. Specimens were collected in RNAlater ${ }^{\circledR}$ Solution (Life Technologies Australia Pty Ltd., Mulgrave, VIC, Australia), and stored first at $4^{\circ} \mathrm{C}$ and then, after removal of RNALater ${ }^{\circledR}$ solution, at $-80^{\circ} \mathrm{C}$ for later protein/RNA extraction. For immunohistochemical analyses, sections of affected corneas, used for histopathological diagnosis following corneal transplantation, and of normal corneas obtained through the Eye Bank of South Australia, were used.

\subsection{Protein extraction}

Each CE-DM specimen was washed thrice with $100 \mu \mathrm{L}$ Ultrapure Water (Cascada ${ }^{\mathrm{AN}}$ water; PALL Corporation), incubated in $100 \mu \mathrm{L}$ Ultrapure Water for 20 minutes at RT to allow osmotic lysis of cells, and proteins extracted by chemical cleavage and hydroxylamine and guanidine-hydrochloride treatment. Chemical cleavage was performed with $140 \mu \mathrm{l} \mathrm{98 \%} \mathrm{formic} \mathrm{acid} \mathrm{and} 1 \mathrm{mg}$ cyanogen bromide at $30^{\circ} \mathrm{C}$ overnight. The sample was dried under vacuum and homogenised in $75 \mu$ extraction buffer (2M hydroxylamine and 6M Guanidine-HCl, pH 9)) using a TissueLyser (Retsch $\mathrm{GmbH} \& \mathrm{CO} . \mathrm{KG}$, Haan, Germany) The homogenate was incubated (4 hours at $45^{\circ} \mathrm{C}$ )_ and spun (10 minutes at $18,000 \times \mathrm{g}$ ) to collect supernatant. The lysate was buffer exchanged to nUPLC-MSE compatible buffer (1.6 M urea, $100 \mathrm{mM}$ Tris-HCl, pH 7.5) using Vivaspin 500 columns (3,000 kDa, PES membrane; Sartorius, Melbourne, Australia). The resulting protein extract was quantified by EZQ Protein Quantitation (Molecular Probes, Eugene, Oregon, USA) method following the manufacturer's protocol.

\subsection{Comparative mass spectrometry}

To perform nUPLC-MSE (nanoscale ultra-performance liquid chromatography-mass spectrometry), $15.26 \mu \mathrm{g}$ of proteins in $20 \mu \mathrm{L}$ of solution was trypsin-digested as 
previously described ${ }^{25}$. Briefly, the extract was reduced and alkylated by sequentially adding $2 \mu \mathrm{L}$ of $100 \mathrm{mM} \mathrm{DTT}$ ( $60 \mathrm{~min}$ at $37^{\circ} \mathrm{C}$ ) and $2.5 \mu \mathrm{L}$ of $200 \mathrm{mM}$ iodoacetamide (IAA; 60 min at RT). $0.5 \mu \mathrm{L}$ of DTT ( $10 \mathrm{~min}$ at $37^{\circ} \mathrm{C}$ ) was added before the trypsin to avoid protease alkylation. Finally, $1 \mu \mathrm{L}$ of sequencing grade trypsin (Promega, Madison, WI, USA) at $0.5 \mathrm{mg} / \mathrm{mL}$ was added and let react for 16 hours at $37^{\circ} \mathrm{C}$. The reaction was quenched by adding $1 \mu \mathrm{L}$ of $10 \%$ formic acid (30 min at $37^{\circ} \mathrm{C}$ ). The samples were diluted with aqueous formic acid $0.1 \%$ to a final peptide concentration of $0.5 \mathrm{mg} / \mathrm{mL}$ and MassPrep yeast enolase digestion standard (SwissProt P00924; Waters, Milford, MA, USA) was added as internal standard to a final concentration of $100 \mathrm{fmol} / \mu \mathrm{L}$.

Chromatographic separation was achieved on a nanoACQUITY UPLC System (Waters) by injecting $2 \mu \mathrm{L}$ of sample per run. The samples were loaded on a $5 \mu \mathrm{m}$ Symmetry $\mathrm{C}_{18}$ trapping column $180 \mu \mathrm{m} \times 20 \mathrm{~mm}$ (Waters) and separated on a 1.7 $\mu \mathrm{m}$ BEH $130 \mathrm{C}_{18}$ Nano Ease $75 \mu \mathrm{m} \times 250 \mathrm{~mm}$ LC column (Waters) at a flow rate of $250 \mathrm{~nL} / \mathrm{min}$ using a gradient from 3 to $40 \% \mathrm{CH} 3 \mathrm{CN}$ in $145 \mathrm{~min}$. The lock mass ([Glu1]-Fibrinopeptide B, Sigma, $500 \mathrm{fmol} / \mathrm{mL}$ ) was delivered from the auxiliary pump of the UPLC at a constant flow rate of $600 \mathrm{~nL} / \mathrm{min}$.

Separated peptides were introduced into the hybrid quadrupole orthogonal acceleration time-of-flight mass spectrometer (Q-Tof Premier, Waters) through the nano ESI interface. The instrument was programmed to step between low (4 eV) and high (15-40 eV) energy in the collision cell, using a scan time of $1.5 \mathrm{~s}$ per function over a mass range of $50-1990 \mathrm{~m} / \mathrm{z}$. Data were acquired using the Waters proprietary data-independent parallel parent and fragment ion acquisition mode (Expression - MSE) ${ }^{26}$. Continuum LC-MS data from three technical replicates for each sample were processed for qualitative and quantitative analysis using the software ProteinLynx Global Server v. 2.4 (PLGS, Waters Corp.). 
Qualitative identification of proteins was obtained using the embedded ion accounting algorithm of PLGS 2.4 (Waters), searching the UniProt KB/ Swiss-Prot Protein Knowledgebase release 2013_08, 24-July-13, consisting of 540732 entries and 192091492 residues, abstracted from 221115 references and using the Human taxonomical restriction (20266 sequences), to which the sequence of $S$. cerevisiae Enolase was appended (UniProtKB/Swiss-Prot AC: P00924) ${ }^{27}$. The search parameters included: automatic tolerance for precursor ions and for product ions, at least 3 fragment ions matched per peptide, and 7 fragment ions matched per protein, at least 2 peptides matched per protein, 1 missed cleavage allowed, carbamidomethylation of cysteine as fixed modification and oxidation of methionine as variable modification. The false positive rate (FPR) was fixed below $4 \%$ for protein identification and the concentration of the calibration protein (internal standard Enolase from Yeast) was set to $200 \mathrm{fmol}$.

The label-free quantitative analysis was performed on three technical replicates of each biological replicate of each experimental condition. Within the differential analysis, the EMRT (Exact Mass Retention Time) cluster tables (list of peptide Exact Masses paired to their Retention Times) and the Protein tables were generated upon normalization to the most reproducible peptides of yeast Enolase (Swiss-Prot AC: P00924) for retention time and intensity ( $\mathrm{m} / \mathrm{z}$ 975.56, $\mathrm{m} / \mathrm{z}$ 1038.59, $\mathrm{m} / \mathrm{z}$ 1088.65, $\mathrm{m} / \mathrm{z} 1435.75$ and $\mathrm{m} / \mathrm{z}$ 1988.035). Quantitative analysis was performed based on 164086 molecular spectral features using the EMRT cluster annotation. The differentially expressed proteins dataset was filtered by considering only those identifications from the alternate scanning LC- MSE data exhibiting a good replication rate (at least 4 out of 6 injections, 66.7\%) and with $p<0.05$ for the relative protein fold change (two-tailed Student's t-test). The significance of regulation level was specified at $30 \%$, hence 1.3 -fold ( 0.26 on a natural log scale), which is typically $2-3$ 
times higher than the estimated error on the intensity measurement, and used as a threshold to identify significant up- or down-regulation ${ }^{26}$.

\subsection{I mmunohistochemistry}

Paraffin-embedded sections of FECD and normal corneas were immunolabelled for the APOE and IGHGI proteins as previously described ${ }^{28}$, following alkaline antigen retrieval (1×Dako Target Retrieval Solution, pH 9; Dako Australia Pty Ltd, Scoresby, VIC, Australia). For retrieval, slides were placed in retrieval buffer pre-heated to boiling temperature, for an hour at $100^{\circ} \mathrm{C}$. Sections were cooled ( 1 hour at RT), washed in 1× TBS (Tris-Buffered Saline) and then incubated with the mouse monoclonal anti-human APOE (1:2000; cat\#NE1004; Calbiochem, Merck Pty, VIC, Australia) or rabbit monoclonal anti-human IGHG1 (1:30,000 (eye), 1:6000 (tonsil); cat\#MABN1055; Merck Millipore, Bayswater, VIC, Australia) primary antibody, at $4^{\circ} \mathrm{C}$ overnight followed by incubation with NovoLink Polymer complex reagent (Leica Microsystems, Bannockburn, IL, USA; 1 hour at RT). Antibody binding was detected with Liquid DAB+ substrate Chromogen System (K3468; Dako Australia Pty Ltd). Sections were counterstained with haematoxylin and mounted in DePeX (Merck KGaA, Darmstadt, Germany). Imaging was performed on an Olympus BX50 microscope fitted with QImaging Micropublisher RTV 5 Megapixel Digital Camera using QCapture Imaging software (Olympus Corporation, Tokyo, Japan).

\subsection{Quantitative reverse transcription-polymerase chain reaction (qRT- PCR)}

Total RNA was extracted from pools of affected CE-DM ( $n=3$ per pool), and individual normal equivalent specimens using Trizol reagent (Invitrogen, Carlsbad, CA, USA) and RNeasy mini-kit (Qiagen, Valencia, CA, USA), according to the manufacturer's protocol. On-column DNase I (DNA-free, Ambion, Austin, TX, USA) treatment was performed to degrade any genomic DNA. For cDNA synthesis, 0.26 
$\mu \mathrm{g}$ of total RNA was reverse-transcribed using SuperScript III First-Strand Synthesis System (Invitrogen) and random hexamer primers. CDNA standards with and without reverse transcriptase ( $\mathrm{RT}^{+}$and $\mathrm{RT}^{-}$, respectively) were synthesised from pooled RNA of all the analysed samples. $A P O E$ mRNA was amplified using gene-specific primers (Forward: 5'-TTGCTGGTCACATTCCTGG-3'; Reverse: 5'-CAGGTAATCCCAAAAGCGAC$\left.3^{\prime}\right) ; \quad$ primer sequences were retrieved from Primer Depot (http://primerdepot.nci.nih.gov/cgi-bin/testdb.pl). qRT-PCR was performed on a StepOne Plus real-time PCR system (Applied Biosystems, Foster City, CA, USA) using $\mathrm{RT}^{2}$ SYBR $^{\mathrm{R}}$ Green Rox ${ }^{\mathrm{TM}}$ master mix (SABiosciences). Each sample was analysed in duplicate. Amplification was performed as follows: enzyme activation at $95^{\circ} \mathrm{C}$ for 10 minutes followed by 40 cycles of denaturation at $95^{\circ} \mathrm{C}$ for 15 seconds, and annealing and extension at $64^{\circ} \mathrm{C}$ for 30 seconds. Data were analysed using the StepOne Plus software. Amplification efficiency $(E)$ was determined as previously described, and gene expression normalised against Beta-actin (ACTB) expression using the Q-gene method $^{29}$; with adjustment for $E$. Data is expressed as mean normalised expression (MNE) \pm standard error of mean (SEM). Statistical analysis was performed using Student's $t$-test with significance level set at 0.05 .

\subsection{Bioinformatic analysis}

Functional relationships between APOE, IGHG1 and all the genes/proteins implicated in FECD (Supporting Table 1) were explored using Network Analyst (www.networkanalyst.ca). Protein-protein interactions were analysed using the IMEx Interactome database, which contains literature-curated comprehensive data from InnateDB (http://www.innatedb.com) ${ }^{30}$. Both zero-order (direct) and first-order (indirect) interaction networks were generated. Module analysis tool was used to reveal functionally related modules within the networks. In addition, regulatory transcription factor-gene interactions were analysed using the ENCODE ChiP-seq data ${ }^{30}$ and default settings. 


\section{RESULTS}

\subsection{Differentially abundant proteins in FECD-affected Descemet's membrane}

In this study, nUPLC-MSE isotope free shotgun profiling was employed to identify differentially abundant proteins between FECD-affected and normal corneal DM. Surgical specimens from three patients and three sex-matched control specimens were used for analysis (Table 1). The donors of control specimens were older than the patients by design (72-96 and 64-78 years old, respectively), to minimise the possibility of un-manifested disease in controls.

Table 1: Age and sex of patients and donors whose corneal endotheliumDescemet's membrane specimens were used in this study. FECD, Fuchs' endothelial corneal dystrophy; $F$, female; $M$, male; NA, not applicable; qRT-PCR, quantitative real-time polymerase chain reaction.

\begin{tabular}{|c|c|c|c|}
\hline Sample & Age & Sex & Pool \\
\hline \multicolumn{4}{|c|}{ Comparative proteomics } \\
\hline FECD 1 & 64 & M & \multirow{6}{*}{ NA } \\
\hline FECD 2 & 78 & $\mathrm{~F}$ & \\
\hline FECD 3 & 75 & M & \\
\hline Control 1 & 96 & $M$ & \\
\hline Control 2 & 72 & M & \\
\hline Control 3 & 88 & $\mathrm{~F}$ & \\
\hline \multicolumn{4}{|c|}{ qRT-PCR } \\
\hline FECD 1 & 58 & $\mathrm{~F}$ & \multirow{3}{*}{1} \\
\hline FECD 2 & 64 & $\mathrm{~F}$ & \\
\hline FECD 3 & 67 & $M$ & \\
\hline FECD 4 & 49 & $\mathrm{~F}$ & \multirow{3}{*}{2} \\
\hline FECD 5 & 72 & $\mathrm{~F}$ & \\
\hline FECD 6 & 82 & M & \\
\hline
\end{tabular}




\begin{tabular}{|lll|}
\hline FECD 7 & 63 & $\mathrm{~F}$ \\
\hline FECD 8 & 78 & $\mathrm{M}$ \\
\hline FECD 9 & 81 & $\mathrm{M}$ \\
\hline Control 1 & 41 & $\mathrm{M}$ \\
\hline Control 2 & 81 & $\mathrm{M}$ \\
\hline Control 3 & 64 & $\mathrm{M}$
\end{tabular}$\quad \mathrm{NA}$

Expression analysis for abundance of proteins identified in FECD and control samples was performed by the PLGS Expression Analysis Software (Waters Corp.) using peptide ion peak intensities observed in the low collision energy mode in triplicates of each sample. The method has been extensively described ${ }^{31}$ and depends on the relationship between MS signal and the corresponding protein concentration in the peptide analyte signal from each EMRT cluster component. The proteins identified in the three pairs of samples are shown in Table 2. A total of 55 proteins were identified. Of these, 18 proteins were identified both in disease and control samples, 15 only in disease, and 22 only in control samples.

Table 2: Proteins identified in FECD-affected and/or control Descemet's membrane by nUPLC-MSE. Protein name, symbol and accession number in the UniProt $\mathrm{KB} /$ Swiss-Prot databases are given. The score indicates a measure of the degree of match between identified peptides of a protein and their experimental MS/MS spectra. The peptide with the best score was ranked the highest and considered as the identification result. Sample type in which a protein was identified is indicated. FECD, Fuchs' endothelial corneal dystrophy. 


\begin{tabular}{|lllll|}
\hline \multicolumn{1}{|c}{ Protein name } & Protein Symbol & $\begin{array}{l}\text { Accession } \\
\text { number }\end{array}$ & Score & Sample type \\
\hline $\begin{array}{l}\text { Transforming growth factor beta induced } \\
\text { protein }\end{array}$ & TGFBI & Q15582 & 1135.53 & FECD and Control \\
\hline Actin gamma enteric smooth muscle & ACTG2 & P63267 & 674.26 & FECD and Control \\
\hline Actin alpha skeletal muscle & ACTA1 & P68133 & 668.77 & FECD \\
\hline Ig kappa chain C region & IGKC & P01834 & 547.01 & FECD and Control \\
\hline Apolipoprotein E & APOE & P02649 & 536.23 & FECD and Control \\
\hline Histone H4 & HIST1H4A & P62805 & 529.96 & Control \\
\hline Actin cytoplasmic 1 & ACTB & P60709 & 468.76 & FECD and Control \\
\hline Actin cytoplasmic 2 & ACTG1 & P63261 & 468.76 & Control \\
\hline Serum amyloid P component & APCS & P02743 & 441.77 & Control \\
\hline Ig gamma 2 chain C region & IGHG2 & P01859 & 438.26 & FECD and Control \\
\hline Ig gamma 1 chain C region & IGHG1 & P01857 & 413.86 & FECD and Control \\
\hline POTE ankyrin domain family member F & POTEF & A5A3E0 & 377.87 & FECD and Control \\
\hline C-Type Lectin Domain Family 11, Member A & CLEC11A & Q9Y240 & 359.89 & FECD and Control \\
\hline Ig gamma 3 chain C region & IGHG3 & P01860 & 325.79 & FECD and Control \\
\hline Putative beta actin like protein 3 & POTEKP & Q9BYX7 & 290.45 & Control \\
\hline Fibulin 5 & FBLN5 & Q9UBX5 & 272.85 & FECD and Control \\
\hline Serine protease HTRA1 & HTRA1 & Q92743 & 227.26 & FECD and Control \\
\hline Beta actin like protein 2 & ACTBL2 & Q562R1 & 200.06 & Control \\
\hline Prostaglandin H2 D isomerase & PTGDS & P41222 & 193.47 & Control \\
\hline Transmembrane protein 179 & TMEM179 & Q62VK1 & 193.43 & Control \\
\hline POTE ankyrin domain family member I & POTEI & P0CG38 & 186.8 & Control \\
\hline
\end{tabular}

This article is protected by copyright. All rights reserved. 


\begin{tabular}{|lllll|}
\hline Ig alpha 1 chain C region & IGHA1 & P01876 & 185.2 & FECD and Control \\
\hline Complement component C9 & C9 & P02748 & 176.98 & FECD and Control \\
\hline Serum albumin & ALB & P02768 & 176.2 & Control \\
\hline Actin related protein 3C & ACTR3C & Q9C0K3 & 173.01 & FECD \\
\hline Alpha 1 antitrypsin & SERPINA1 & P01009 & 170.57 & Control \\
\hline Tachykinin 3 & TAC3 & Q9UHF0 & 147.51 & FECD \\
\hline Fibulin 1 & FBLN1 & P23142 & 144.71 & Control \\
\hline Reticulocalbin 3 & RCN3 & Q96D15 & 143.26 & FECD \\
\hline TPT1 like protein & TPT1-Like protein & Q56UQ5 & 142.72 & FECD \\
\hline Vimentin & VIM & P08670 & 138 & FECD \\
\hline HAUS augmin like complex subunit 3 & HAUS3 & Q68CZ6 & 126.16 & FECD \\
\hline Clusterin & CLU & P10909 & 125.29 & FECD and Control \\
\hline Collagen alpha 5 IV chain & COL4A5 & P29400 & 122.17 & FECD \\
\hline Apolipoprotein D & APOD & P05090 & 112.68 & Control \\
\hline Eukaryotic translation initiation factor 5A & EIF5A & P63241 & 112.33 & Control \\
\hline Thrombospondin 4 & THBS4 & P35443 & 111.56 & Control \\
\hline Keratocan & KERA & O60938 & 109.67 & FECD and Control \\
\hline Extracellular superoxide dismutase & SOD3 & P08294 & 108.53 & Control \\
\hline Collagen alpha 3 IV chain & COL4A3 & Q01955 & 99.62 & FECD and Control \\
\hline Keratin type I cytoskeletal 20 & KRT20 & P35900 & 97 & Control \\
\hline Lipid phosphate phosphohydrolase 2 & PPAP2C & O43688 & 94.56 & FECD \\
\hline Ig alpha 2 chain C region & IGHA2 & P01877 & 93.1 & Control \\
\hline Collagen alpha 1 VIII chain & COL8A1 & P27658 & 92.44 & FECD and Control \\
\hline Protein FAM90A1 & FAM90A1 & Q86YD7 & 91.71 & Control \\
\hline
\end{tabular}

This article is protected by copyright. All rights reserved. 


\begin{tabular}{|lllll|}
\hline GTP binding protein SAR1a & SARIA & Q9NR31 & 87.48 & FECD \\
\hline $\begin{array}{l}\text { Leucine rich repeat and fibronectin type III } \\
\text { N3 }\end{array}$ & LRFN3 & Q9BTN0 & 83.57 & FECD \\
\hline Collagen alpha 1 IV chain & COL4A1 & P02462 & 79.83 & FECD \\
\hline Cyclin D1 binding protein 1 & CCNDBP1 & O95273 & 79.51 & Control \\
\hline Homeobox protein Hox B2 & HOXB2 & P14652 & 73.88 & Control \\
\hline Transcription factor 25 & TCF25 & Q9BQ70 & 73.16 & FECD \\
\hline E3 ubiquitin protein ligase MARCH11 & MARCH11 & A6NNE9 & 70.44 & Control \\
\hline mRNA decapping enzyme 1A & DCP1A & Q9NPI6 & 69.44 & Control \\
\hline Cadherin 12 & CDH12 & P55289 & 64.08 & FECD \\
\hline
\end{tabular}


To quantify identified proteins for differential abundance, the dataset was filtered by considering only those identifications from the alternative scanning LC-MS ${ }^{E}$ data exhibiting a good replication rate and significant relative protein fold change. A total of 8 proteins met these criteria (Table 3 ).

Table 3: Differentially abundant proteins identified by nUPLC-MS ${ }^{\mathrm{E}}$ between FECDaffected and unaffected Descemet's membrane. Protein name, symbol, accession number in the UniProt KB/Swiss-Prot databases and ratio of signal intensities of identified peptides indicating relative abundance in affected versus unaffected specimens, are given. The two-tailed Student's t-test p-value for each comparison is also given. Significant differences are marked with asterisks.

\begin{tabular}{|lllll|}
\hline Protein name & $\begin{array}{l}\text { Protein } \\
\text { symbol }\end{array}$ & $\begin{array}{l}\text { Accession } \\
\text { number }\end{array}$ & Ratio & $\begin{array}{l}\text { P- } \\
\text { value }\end{array}$ \\
\hline $\begin{array}{l}\text { Transforming growth factor beta } \\
\text { induced }\end{array}$ & TGFBI & Q15582 & 0.84 & $>0.05$ \\
\hline Clusterin & CLU & P10909 & 0.81 & $>0.05$ \\
\hline Ig gamma 1 chain C region & IGHG1 & P01857 & $0.4^{*}$ & $<0.05$ \\
\hline Apolipoprotein E & APOE & P02649 & $0.3^{*}$ & $<0.05$ \\
\hline $\begin{array}{l}\text { POTE ankyrin domain family member } \\
1\end{array}$ & POTEl & P0CG38 & NA & NA \\
\hline Histone H4 & HIST1H4A & P62805 & NA & NA \\
\hline Beta actin like protein 2 & ACTBL2 & Q562R1 & NA & NA \\
\hline Serum albumin & ALB & P02768 & NA & NA \\
\hline
\end{tabular}

$\mathrm{NA}$, not applicable because protein identified only in control samples.

The significance of regulation level specified at 30\%, which is typically 2-3 times higher than the estimated error on the intensity measurement, was used as a threshold to identify significant up- $(\geq 1.3$-fold) or down-regulation ( $\leq 0.7$-fold). Only IGHGI and APOE met these criteria and showed relatively lower abundance, 0.4 and 0.3 fold, respectively, in affected compared to control DM. 
To validate differential abundance of APOE and IGHGI proteins, semi-quantitative Western blotting could not be performed because it was not sensitive to detect these proteins in DM (data not shown). Using immunohistochemistry, we previously discovered differential distribution of TFGBI and CLU proteins between FECDaffected and unaffected corneas ${ }^{28}$. We adopted the same approach in this study and determined any differences in distribution of APOE and IGHGI between FECDaffected and normal corneas, particularly DM.

\subsection{Differential distribution of APOE and IGHG1 proteins in FECD-affected corneas}

To compare distribution of APOE and IGHGI proteins between FECD-affected and unaffected corneas, immunolabelling was performed on sections of affected and normal corneas using anti-APOE and anti-IGHGI antibodies, respectively. Positive APOE labelling was observed in the CE, DM, stroma and corneal epithelium in both affected and normal corneas (Figure 1, left and middle panels). Absence of similar labelling in sections upon omitting the primary antibody, proved signal specificity (Figure 1, right panels). Immunolabelling showed some differences in APOE distribution between affected and unaffected corneas. In DM, in affected corneas, the protein distributed mainly in the anterior face and was absent in the posterior aspect whereas in normal corneas it was distributed in the anterior face and throughout the thickness of the membrane (Figure 1, DM, bottom left and middle panels, arrows). The DM was thicker in affected compared to normal corneas, consistent with abnormal thickening in the disease.

Figure 1: Localisation of Apolipoprotein E (APOE) in FECD-affected (left panels; Fuchs') and normal (middle panels; Control) corneas. Sections of corneas were immunolabelled with a mouse monoclonal anti-human APOE antibody and counterstained with haematoxylin to visualise nuclei. In normal cornea, strong 
positive labelling was observed throughout the corneal endothelium (CE) compared to interrupted staining, consistent with endothelial degeneration, in FECD-affected cornea (left and middle bottom panels, arrowheads). The protein distributed in the anterior face of thickened Descemet's membrane (DM) in affected cornea but was uniformly distributed in DM in normal cornea (left and middle bottom panels, arrows). APOE-positive labelling was seen in the stroma (S) in both affected and normal corneas but labelling was more prominent in normal cornea (left and middle panels). APOE labelling was absent in the Bowman's layer (BL) in both normal and FECD-affected corneas (left and middle top panels). Diffused APOE labelling was seen in the epithelium (Epi) in both affected (Fuchs') and normal corneas (left and middle top panels). Absence of labelling in normal corneal sections by omitting the primary antibody (right panels) proved signal specificity. Images are at $\times 400$ magnification. Representative images from three independent experiments on independent specimens are shown.

Strong APOE-positive labelling was observed throughout the CE in control corneas (Figure 1, CE, bottom middle panel, arrowheads), loss of endothelial cells precluded ascertainment of labelling in affected corneas although remnant cells were positive (Figure 1, CE, bottom left panel, arrowhead). Labelling in the stroma was weaker in affected than in control corneas (Figure 1, S, left and middle panels). The labelling showed diffused distribution of the protein in the epithelium, primarily basal epithelium, in both affected and normal corneas (Figure 1, Epi, top left and middle panels). No APOE-positive labelling was observed in the Bowman's layer (BL) in affected and control corneas (Figure 1, BL, top left and middle panels). Expression pattern of APOE suggests the role of this protein throughout the cornea. Differential distribution between FECD-affected and normal DM is consistent with lower abundance of the protein in diseased DM detected by comparative mass spectrometry. 
I mmunolabelling for IGHGI showed strong positive labelling in the CE in both FECDaffected and normal corneas (Figure 2, CE, left and middle panels, arrowheads). No or weak labelling was observed in endothelial cells overlying the guttae in affected corneas (Figure 2, CE, left panel, arrow). No IGHG1-positive labelling was observed in DM in affected corneas and only weak labelling observed in normal corneas (Figure 2, DM, bottom left and middle panels).

Figure 2: Localisation of immunoglobulin heavy constant gamma 1 protein (IGHG1) in FECD-affected (left panels: Fuchs') and normal (middle panels; Control) corneas. Sections of corneas were immunolabelled with a rabbit monoclonal anti-human IGHGI antibody and counterstained with haematoxylin to visualize nuclei. Strong IGHGI-positive labelling was observed throughout the corneal endothelium (CE) in both normal and affected corneas (left and middle bottom panels, arrowheads); the labelling over the guttae was weak (bottom left panel, arrow). No IGHG1-positive labelling was observed in the thickened (as expected) Descemet's membrane (DM) in affected cornea and only weak labelling in DM in normal cornea (left and middle bottom panels). In stroma (S), IGHG1 labelling was seen only in control corneas and not in affected corneas (left and middle panels). A distinctive labelling of the protein was observed at the anterior border of the stroma adjacent to Bowman's layer (BL) but not in BL in affected and normal corneas (left and middle top panels). Strong IGHGI-positive labelling was observed in corneal epithelium (Epi) in both FECDaffected and unaffected corneas. Diffused cytoplasmic labelling was seen in affected corneas (Epi, top left panel) compared to prominent labelling between adjacent basal epithelial cells and in the cytoplasm in normal corneas (Epi, top middle panel). Absence of IGHGI labelling in control corneal sections upon omitting the primary antibody proved signal specificity. I mages are at $\times 400$ magnification. Representative images from three independent experiments on independent specimens are shown. 
IGHGI labelling in the stroma was strikingly different between diseased and normal corneas with no labelling in the former compared to strong positive labelling in the latter (Figure 2, S, left and middle top and bottom panels). In addition, distinctively positive labelling was observed at the anterior face of the stroma, adjacent to the $\mathrm{BL}$ in normal corneas (Figure 2, top middle panel). No IGHG1-positive labelling was observed in the BL in affected or control corneas (Figure 2, BL, top left and middle panels). In the corneal epithelium, strong IGHG1-positive labelling was present in both affected and control corneas (Figure 2, Epi, top left and middle panels). However labelling in the former indicated cytoplasmic localisation of the protein (Figure 2, Epi, top left panel) whereas in the latter the protein was predominantly present in basal epithelial cells at the cellular periphery between adjacent cells and some in the cytoplasm (Figure 2, top middle panel). Absence of similar labelling in control corneas without primary antibody hybridisation proved signal specificity. Pattern of IGHGI expression in the normal cornea indicates its role in all the layers of the cornea. Undetectable expression in FECD-affected and very weak expression in normal DM correlates with lower abundance of the protein, detected by comparative mass spectrometry, in affected DM.

\subsection{Differential expression of $A P O E$ transcript in FECD-affected corneal endothelium}

As DM is laid down by the CE, we hypothesised that differential abundance of APOE and IGHGI proteins in DM in FECD is due to differential expression of the encoded transcripts in the $C E$, in the disease. Thus, we investigated relative expression of $A P O E$ and IGHGI mRNA between affected and normal CE using qRT-PCR. Due to fewer endothelial cells in affected than unaffected corneas, mRNA expression was compared between pools of affected and individual unaffected specimens (Table 1). 
The affected specimens were from patients aged $49-82$ years and unaffected specimens from donors aged 41-81 years. Both sexes and age-range were represented in each affected pool to avoid confounding effects of these variables on expression levels. The analysis revealed significantly lower levels of APOE mRNA in FECD-affected than unaffected CE (Figure 3; $p=0.035$ ), consistent with lower abundance of the encoded protein in affected DM, thus proving our hypothesis. Extremely low level expression of IGHGI mRNA in the CE, ascertained from mRNASeq analysis of normal human ocular tissues (to be published elsewhere) precluded comparative analysis. The mRNASeq analysis revealed very low-level expression of IGHGI mRNA in the CE compared to ACTB mRNA, and compared to other ocular tissues (Table 4), which correlates with no and very weak expression of the encoded protein in DM in FECD-affected and unaffected corneas, respectively, detected by immunolabelling (Figure 2 ).

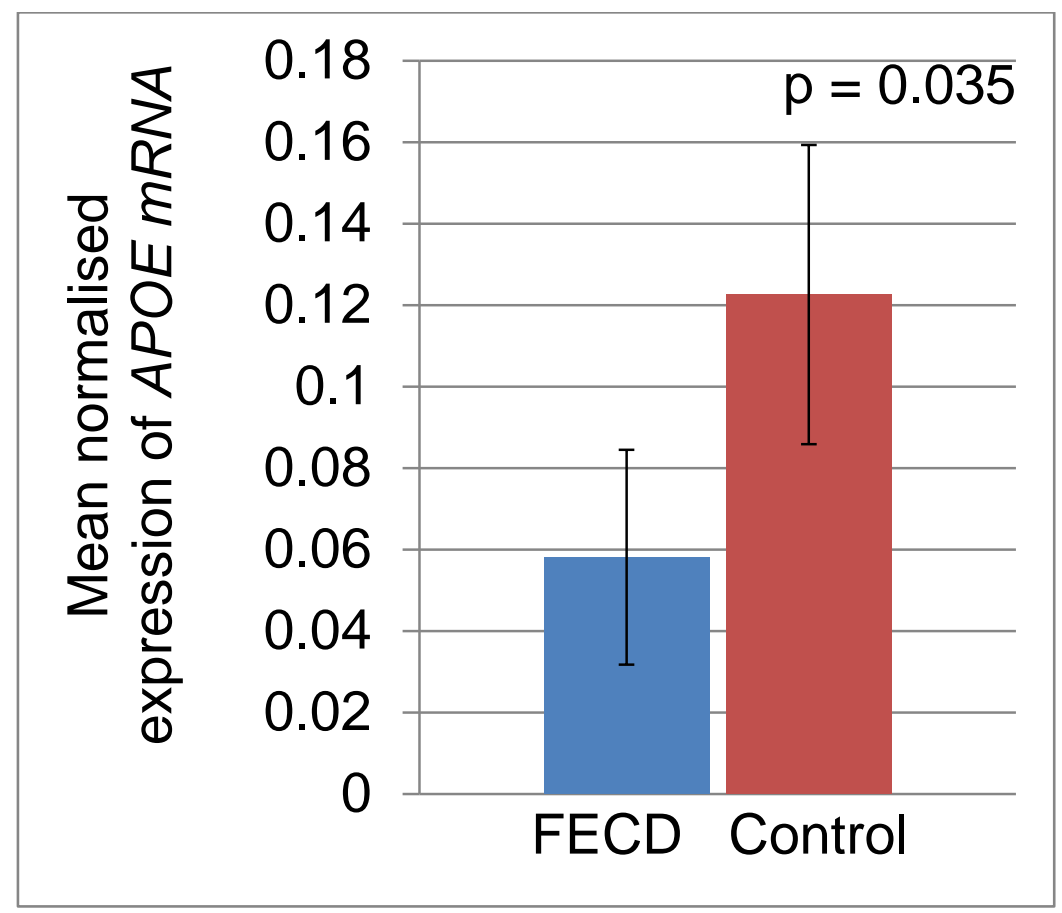

Figure 3: Relative $A P O E$ mRNA expression levels in FECD-affected and normal 
corneal endothelium. APOE mRNA expression was analysed in three pairs of affected and unaffected corneal endothelium by qRT-PCR (see Materials and Methods), and normalised against $A C T B$ expression. The data are presented as mean normalised expression \pm standard error of the mean (SEM). The data was statistically analysed using Student's t-test. FECD, Fuchs' endothelial corneal dystrophy. 
Table 4: Expression of IGHGI and $A C T B$ mRNA in normal human ocular tissues including corneal endothelium detected by RNASeq. Normalized level of expression is indicated as counts per million.

\begin{tabular}{|c|c|c|c|c|c|c|c|c|c|}
\hline \multirow[b]{2}{*}{ Ensemble I D } & \multirow[b]{2}{*}{ Gene } & \multicolumn{8}{|c|}{ Counts per million } \\
\hline & & $\begin{array}{c}\text { Corneal } \\
\text { epithelium }\end{array}$ & $\begin{array}{l}\text { Corneal } \\
\text { stroma }\end{array}$ & $\begin{array}{c}\text { Corneal } \\
\text { endothelium }\end{array}$ & $\begin{array}{l}\text { Trabecular } \\
\text { meshwork }\end{array}$ & $\begin{array}{l}\text { Ciliary } \\
\text { body }\end{array}$ & Retina & $\begin{array}{c}\text { Optic } \\
\text { nerve } \\
\text { head }\end{array}$ & $\begin{array}{l}\text { Optic } \\
\text { nerve }\end{array}$ \\
\hline ENSG00000075624 & $A C T B$ & 1737.051 & 1350.404 & 436.662 & 2780.927 & 2304.637 & 1433.238 & 1833.165 & 2041.532 \\
\hline
\end{tabular}




\subsection{Functional relationship of APOE and IGHGI with genes/proteins associated with FECD}

To understand the role of APOE and IGHGI in FECD, and to explore their functional relationships with the genes/proteins implicated in the disease, network analysis was performed (see Methods). The recently reported genes differentially expressed in FECD-affected $\mathrm{CE}^{32}$ were not included in the analysis because they are yet to be independently replicated. The analysis to determine direct protein-protein interactions among the FECD genes/ proteins revealed one subnetwork comprising of 14 nodes (genes/proteins) including APOE, and 17 edges (interactions) with FN1, JUN and PRDX2 as the hub nodes, the proteins with the most number of interactions (Figure 4 and Supporting Table 2). It also showed that APOE is known to interact with PRDX2. The subnetwork comprised of two modules of functionally related genes. The first module included APOE and eight other nodes, mainly extracellular proteins and peroxiredoxin enzymes $(p=0.00125)$, and the second, JUN, TP53, CDKN1A, CDKN2A and EDN1 ( $p=0.0285$ ). The analysis to determine direct as well as indirect protein-protein interactions among the FECD genes/proteins also revealed a single subnetwork that comprised of 1968 nodes including 29 disease genes/proteins with APOE, and 2957 edges (not shown). A minimum network was constructed to reduce the complexity of this subnetwork and to reveal minimum connected interactions. It comprised of 74 nodes including the same 29 FECD genes/ proteins as the original subnetwork, and 211 edges with TP53, JUN and FN1 as the main hub nodes (Figure 5 and Supporting Table 3).

Figure 4: Network of direct protein-protein interactions among the genes/proteins implicated in FECD. The network was generated from zero-order network analysis of the implicated genes. Nodes (dots) indicate genes/proteins and edges (lines) indicate interactions. Hub nodes are in red. Node size and colour is proportionate to degree of connectivity or number of interactions with red, orange, yellow and white 
indicating decreasing number of interactions in that order. Note the interaction between PRDX2 and APOE shown by this network.

Figure 5: Network of direct and indirect protein-protein interactions among the genes/proteins implicated in FECD. The network was generated from first-order network analysis of the implicated genes and trimmed to reveal the minimum connected network; UBC was removed to reduce network complexity. Nodes (dots) indicate genes/proteins and edges (lines) indicate interactions. Hub nodes are in red. Node size and colour is proportionate to degree of connectivity or number of interactions with red, orange and yellow indicating decreasing number of interactions in that order. Nodes that mediate indirect interaction of APOE with the disease genes/proteins are in blue.

Apart from showing the direct interaction between APOE and PRDX2, the network revealed that $A P O E$ is also known to indirectly interact via other molecules with several FECD genes/proteins such as ITGA4, COL1A1, ATP1B1, TP53 and JUN. The minimum network comprised of one significant functional module of 57 nodes including 21 of the disease genes/proteins with APOE $(p=2.08 \mathrm{e}-21)$. To determine regulatory relationships of APOE with the disease genes/proteins, Transcription factor-gene interaction network analysis was performed. This analysis revealed a single subnetwork of 282 nodes and 855 edges with 25 of the nodes being genes/proteins involved in FECD including APOE. To reduce complexity of the subnetwork, a minimum network of interactions was constructed, which comprised 76 nodes including the same 25 nodes as the original subnetwork, and 294 edges with PRDX2, CDKN1A and AGRN as the hub nodes (Figure 6 and Supporting Table 4). It revealed that transcription factors that regulate the disease genes/proteins also regulate $A P O E$. For example, KLF8 regulates PRDX5, AGRN, LAMC1 and APOE; similarly, KLF9 regulates LAMC1, FN1, SLC4A11 and APOE. The minimum network 
was composed of a single significant functional module $(p=5.32 \mathrm{e}-27)$ including the majority of the nodes (71/76), 23 of which were those implicated in the disease and included APOE. None of the network analyses showed interaction of IGHGI with the genes/proteins implicated in the disease.

Figure 6: Transcription factor-gene interaction network of genes/proteins implicated in FECD. The network was generated by transcription factor and target gene interaction analysis of the FECD implicated genes using the ENCODE ChIPseq database and then trimmed to reveal the minimum connected relationships. Nodes (dots and squares) indicate genes/proteins and edges (lines) indicate regulatory interactions. Dots represent disease genes with the exception of PRDX2 and ZEB1, and squares, molecules from the database. Node size and colour is proportionate to degree of connectivity or number of interactions. Red, orange, yellow and white dots indicate decreasing number of interactions in that order. PRDX2, CDKN1A and AGRN are the hub nodes in the network. Transcription factors with regulatory relationships with $\mathrm{APOE}$ are in green.

\section{DISCUSSION}

Quantitative label-free mass spectrometry was successfully employed for identification of differentially abundant proteins between FECD-affected and unaffected DM, in this study. Protein extracts of DM, after removal of corneal endothelial cells, were analysed to identify proteins present only in DM and those differentially abundant in FECD. A total of 55 proteins were identified by mass spectrometry in both affected and unaffected DM. Of these, eight proteins met the criteria for quantitative analysis for determining relative abundance. Of these eight proteins, two, APOE and IGHG1, were found to be significantly differentially abundant in the diseased tissue. Both the proteins were less abundant in FECD- 
affected compared to unaffected Descemet's membrane (Table 3). Consistent with the comparative proteomics finding, immunolabelling of corneal sections revealed relatively confined distribution of APOE in affected DM (Figure 1). Similarly, no IGHG1 was detected in affected DM and very low levels in unaffected DM (Figure 2). Lower abundance of APOE in affected DM was accompanied by down-regulation of $A P O E$ mRNA expression in affected CE (Figure 3). Deregulation of IGHGI expression in the CE in FECD could not be determined due to its extremely low level expression in this tissue. Nevertheless, to the best of our knowledge, this is the first study to report comparative proteomics of DM devoid of corneal endothelial cells, in FECD, and lower abundance of APOE and IGHGI in DM in the disease.

Previously, using conventional 2-D PAGE and Western blotting, TGFBI and Clusterin were reported up-regulated and peroxiredoxin $-2,-3$ and 5 down-regulated in CE-DM complex in FECD ${ }^{20}, 33$. Up-regulation of TGFBI and Clusterin in the diseased CE-DM has been also reported by mass spectrometry-based comparative proteomics analysis ${ }^{34}$. In the present study, TGFBI was found to be the most abundant and Clusterin one of the abundant proteins in DM (Table 2). However, the abundance of both the proteins was not significantly different between diseased and unaffected DM (Table 3). This difference between previous and present findings is most likely due to the difference in the tissue analysed. The previous studies analysed CE-DM complex whereas in the present study CECs were removed and DM analysed. Consistent with the present finding, previously, by immunohistochemistry, we found similar levels of TGFBI and Clusterin proteins in the diseased and unaffected DM but differential distribution of Clusterin between the $\mathrm{two}^{28}$. Contrarily, using immunolabelling technique, Weller et al. detected higher expression of both these proteins in the diseased Descemet's membrane ${ }^{31}$. This discrepancy between our and the latter finding may be due to differences in disease-state of specimens used in the two studies or due to heterogeneity of the disease. 
The present comparative proteomics findings are different than those reported in FECD in an independent study ${ }^{34}$. This is most likely because of the difference in the tissue, types of controls and protein extraction methods used in the two studies. In this study, after removal of CECS, DM proteins were extracted and analysed; Poulsen and colleagues ${ }^{34}$ analysed proteins extracted from CE-DM complex. In the present study, cadaveric DM from normal donors was used as control whereas the reported study ${ }^{34}$ used CE-DM complex from patients with pseudophakic bullous keratopathy as controls. In this study, proteins were extracted by chemical cleavage with cyanogen bromide, formic acid and hydroxylamine and denaturation with guanidine$\mathrm{HCl}$; Poulsen et $\mathrm{al}^{34}$ employed chemical cleavage with cyanogen bromide and denaturation with urea. Many of the proteins identified in Descemet's membrane such as APOD, KERA, COL4A3 and IGHA1 in this study (Table 3) were reportedly as differentially regulated in FECD by Poulsen et $\mathrm{al}^{34}$. Whether they are differentially regulated in the CE or DM in FECD is unknown. Hence the findings of the two studies are complementary but not comparable to each other.

To further understand the importance of lower abundance of APOE and IGHGI in FECD, we compared distribution of these proteins in affected and unaffected corneas. To the best of our knowledge, this is the first study to report APOE expression in the layers of human cornea. Differential distribution of APOE in DM in affected corneas is of particular interest. CE and DM are the main corneal layers affected at the onset of FECD ${ }^{1}$. Normal DM is composed of two distinct layers, the anterior banded layer $(\mathrm{ABL})$ and posterior non-banded layer $(\mathrm{PNBL})^{35}$. The $\mathrm{ABL}$ consists of banded collagens and is laid down in utero ${ }^{35}$. The PNBL is progressively secreted by the CE throughout life ${ }^{35}$. In FECD, the PNBL is significantly attenuated or completely lost due to loss of endothelial cells and is replaced by an additional abnormal banded collagen layer termed posterior collagenous layer (PCL), at the 
extra posterior aspect ${ }^{36}$. The PCL is hypothesised to be secreted by CECs stressed by the damage or disease ${ }^{37}$ that leads to abnormal thickening of DM in FECD. Our work reveals that $A P O E$ is mainly present in the $A B L$ and is absent or present at undetectable levels, in the posterior thickened DM in FECD-affected corneas. This distribution pattern is consistent with downregulation of $A P O E$ gene expression in affected CE (Figure 3). Very low level expression of IGHG1 protein in DM, and the encoding transcript in $\mathrm{CE}$, precluded understanding the significance of lower abundance of this protein in DM in FECD observed by proteomics analysis.

APOE is a widely expressed multifunctional, low-density lipoprotein receptor ligand that primarily serves as a lipid transporter ${ }^{38}$. It also serves as an antioxidant and a regulator of immune and inflammatory responses ${ }^{39}$. IGHG1 is the most common immunoglobulin $G$ protein and an important component of immunological antibodies $^{40}$. It has the highest binding affinity for transporters in human plasma, and plays roles in complement activation or humoral immunity mediated by macromolecules such as complement proteins found in extracellular fluids ${ }^{41-43}$.

Exploration of functional relationships of APOE and IGHG1 with FECD-associated genes/proteins revealed that a protein-protein interaction occurs between APOE and PRDX2 (Figure 4). IGHG1 was not found to interact with any of the analysed genes or proteins likely because only a few literature-curated interactions of this protein are listed in InnateDB indicating that its interaction with these molecules has been yet not determined. Both APOE and PRDX2 are antioxidants. Downregulation of $P R D X 2$ in the CE-DM complex in FECD reported previously ${ }^{33}$, and reduced abundance of $A P O E$ in DM and downregulation of $A P O E$ transcript in the CE discovered in this study suggest that these proteins play roles through a shared mechanism, oxidative stress, in FECD. Oxidative stress is a major pathway implicated in FECD ${ }^{15}$. Consistently, the network analysis revealed PRDX2 to have a central regulatory role 
among the genes/proteins implicated in the disease (Figure 6).

Structurally, APOE consists of two independently folded domains linked by a protease-sensitive loop ${ }^{44}$. These domains reportedly act as high affinity binding sites for proteoglycans ${ }^{45}$ that are major components of $\mathrm{DM}^{35}$ and bear heparin-binding sites $^{45}$. Binding of APOE to heparin sulfate proteoglycans (HSPGs) in cultured smooth muscle cells has been suggested to inhibit excessive extracellular matrix synthesis ${ }^{46}$. HSPGs are secreted by the CE throughout life and are constituents of the $\mathrm{PNBL}^{1,35}$. Interestingly, the PNBL is attenuated or lost in $\mathrm{FECD}^{36}$, and according to our data $A P O E$ is restricted to $A B L$ in diseased as opposed to $A B L$ and PNBL in normal cornea. This suggests that APOE may bind to HPSGs in DM and regulate extracellular matrix production, and downregulation of APOE in FECD may contribute to increased extracellular matrix synthesis in DM in the disease ${ }^{37}$. However, the possibility that lower abundance of this protein in DM is due to attenuation/loss of PNBL in the disease cannot be excluded.

APOE reportedly also binds to the extracellular matrix protein laminin and increases neuronal adhesion in culture ${ }^{47}$. As laminin is present in DM, APOE may play a similar role in the corneal endothelium and its downregulation may contribute to compromised endothelial cell adhesion in FECD.

Furthermore, APOE plays key immuno-regulatory functions, including suppression of $\mathrm{T}$ cell proliferation, regulation of macrophage function, facilitate lipid antigen presentation by CD1 molecules to natural killer $\mathrm{T}$ cells, and modulate inflammation and oxidation ${ }^{48}$. It reportedly regulates blood-brain barrier integrity in Apoe-deficient mice by activating a pro-inflammatory pathway in pericytes ${ }^{49}$. As CE acts as a barrier to entry of aqueous humor in the cornea that is compromised in FECD, downregulation of $A P O E$ may contribute to its breakdown. Interestingly, complement 
activation has been reported to occur in $\mathrm{FECD}^{50}$. Downregulation of $A P O E$ likely also compromises protection of CECs from reactive immuno-modulatory molecules and oxidants leading to cell injury and loss in FECD. Further research is required to understand the role/s of dysregulation of APOE in the disease.

IGHGI and its receptors are expressed in ocular tissues including the CE suggesting its role in conferring immune privilege to the eye ${ }^{40}$. Reduced abundance of IGHGI protein in DM in FECD found in this study and immuno-activation in the disease are consistent with this idea. In addition to its immunological function, IGHGI has been reported to regulate viability of cancer cells as silencing of IGHGI gene in prostate cancer cells inhibits cell growth and increases apoptosis ${ }^{41}$. Whether it also affects viability of CECs needs further research.

In conclusion, through comparative proteomic analysis of FECD-affected and unaffected DM, this study revealed lower abundance of APOE and IGHGI proteins in affected DM and downregulation of APOE mRNA in affected corneal endothelium. Lower levels of APOE likely underlie altered extracellular matrix production, oxidantantioxidant balance, corneal endothelial cell adhesion and/or barrier integrity, and of IGHG1 to compromised local ocular immunity, and contribute to the pathophysiology of FECD.

\section{Acknowledgements}

We thank the patients for their surgical specimens, and the ophthalmologists, the Eye Bank of Victoria (Australia) and Lions Eye Bank of Western Australia, for specimen collection for this research. Thanks are also due to Ms Margaret Philpott and Ms Tamme-Golding-Holbrook for providing donor eye tissue for this study. Assistance from Ms Kim Griggs with tissue sectioning is gratefully acknowledged. 


\section{REFERENCES}

1. Adamis AP, Filatov V, Tripathi BJ , Tripathi RC. Fuchs' endothelial dystrophy of the cornea. Surv Ophthalmol. 1993; 38(2): 149-68.

2. Kenney MC, Labermeier U, Hinds D, Waring GO, 3rd. Characterization of the Descemet's membrane/posterior collagenous layer isolated from Fuchs' endothelial dystrophy corneas. Exp Eye Res. 1984;39(3):267-77.

3. Price MO, Gorovoy M, Benetz BA, et al. Descemet's Stripping Automated Endothelial Keratoplasty Outcomes Compared with Penetrating Keratoplasty from the Cornea Donor Study. Ophthalmology. 2010;117(3):438-44.

4. Riazuddin SA, Zaghloul NA, Al-Saif A, et al. Missense Mutations in TCF8 Cause Late-Onset Fuchs Corneal Dystrophy and Interact with FCD4 on Chromosome 9p. AmJ Human Genet. 2010;86(1):45-53.

5. Santo RM, Yamaguchi T, Kanai A, Okisaka S, Nakajima A. Clinical and histopathologic features of corneal dystrophies in Japan. Ophthalmology. 1995; 102(4):557-67.

6. Omar N, Bou Chacra CT, Tabbara KF. Outcome of corneal transplantation in a private institution in Saudi Arabia. Clin Ophthalmol. 2013;7:1311-8.

7. Williams KA, Keane MC, Galettis RA, Jones VJ, Mills RAD, Coster DJ. The Australian Corneal Graft Registry 2015 Report. Adelaide: Flinders University, Ophthalmology; 2015 2015. Report No.

8. Vithana EN, Morgan PE, Ramprasad V, et al. SLC4A11 mutations in Fuchs endothelial corneal dystrophy. Hum Mol Genet. 2008;17(5):656-66.

9. Baratz $\mathrm{KH}$, Tosakulwong N, Ryu E, et al. E2-2 protein and Fuchs's corneal dystrophy. N EnglJ Med. 2010;363(11):1016-24.

10. Riazuddin SA, Parker DS, McGlumphy Es, et al. Mutations in LOXHD1, a recessive-deafness locus, cause dominant late-onset Fuchs corneal dystrophy. Am J Hum Genet. 2012; 90(3):533-9. 
11. Biswas S, Munier FL, Yardley J, et al. Missense mutations in COL8A2, the gene encoding the a2 chain of type VIII collagen, cause two forms of corneal endothelial dystrophy. Hum Mol Genet. 2001; 10(21):2415-23.

12. Riazuddin SA, Vithana EN, Seet L-F, et al. Missense mutations in the sodium borate cotransporter SLC4A11 cause late-onset Fuchs corneal dystrophya. Hum Mutat. 2010;31(11):1261-8.

13. Wieben ED, Aleff RA, Tosakulwong $\mathrm{N}$, et al. A common trinucleotide repeat expansion within the transcription factor 4 (TCF4, E2-2) gene predicts Fuchs corneal dystrophy. PLoS One. 2012; 7(11):e49083.

14. Afshari NA, Igo RP, Jr., Morris NJ, et al. Genome-wide association study identifies three novel loci in Fuchs endothelial corneal dystrophy. Nature Communications. 2017; 8:14898.

15. Jurkunas UV, Bitar MS, Funaki T, Azizi B. Evidence of oxidative stress in the pathogenesis of fuchs endothelial corneal dystrophy. $\mathrm{Am} /$ Pathol. 2010; 177(5):2278-89.

16. Engler C, Kelliher C, Spitze AR, Speck CL, Eberhart CG, J un AS. Unfolded protein response in fuchs endothelial corneal dystrophy: a unifying pathogenic pathway? AmJ Ophthalmol. 2010;149(2):194-202.e2.

17. Borderie VM, Baudrimont M, Vallée A, Ereau TL, Gray F, Laroche L. Corneal Endothelial Cell Apoptosis in Patients with Fuchs' Dystrophy. Invest Ophthalmol Vis Sci. 2000;41(9):2501-5.

18. Czarny $\mathrm{P}$, Kasprzak E, Wielgorski M, et al. DNA damage and repair in Fuchs endothelial corneal dystrophy. Mol Biol Rep. 2013;40(4):2977-83.

19. Meng H, Matthaei M, Ramanan N, et al. L450W and Q455K Col8a2 knock-in mouse models of Fuchs endothelial corneal dystrophy show distinct phenotypes and evidence for altered autophagy. I nvest Ophthalmol Vis Sci. 2013;54(3):1887-97.

20. Jurkunas UV, Bitar M, Rawe I. Colocalization of increased transforming growth factor-beta-induced protein (TGFBIp) and Clusterin in Fuchs endothelial corneal 
dystrophy. Invest Ophthalmol Vis Sci. 2009;50(3):1129-36.

21. Wyatt A, Yerbury J, Poon S, Dabbs R, Wilson M. Chapter 6: The chaperone action of Clusterin and its putative role in quality control of extracellular protein folding. Adv Cancer Res. 2009; 104:89-114.

22. Kim JE, Kim SJ, Lee BH, Park RW, Kim KS, Kim IS. Identification of motifs for cell adhesion within the repeated domains of transforming growth factor-betainduced gene, betaig-h3. J Biol Chem. 2000;275(40):30907-15.

23. Louttit MD, Kopplin LJ, I go RP, et al. A Multi-Center Study to Map Genes for Fuchs' Endothelial Corneal Dystrophy: Baseline Characteristics and Heritability. Cornea. 2012;31(1):26-35.

24. Krachmer JH, Purcell JJ, Jr., Young CW, Bucher KD. Corneal endothelial dystrophy. A study of 64 families. Arch Ophthalmol. 1978;96(11):2036-9.

25. Pieroni $L$, Finamore $F$, Ronci $M$, et al. Proteomics investigation of human platelets in healthy donors and cystic fibrosis patients by shotgun nUPLC-MSE and 2DE: a comparative study. Mol Biosyst. 2011;7(3):630-9.

26. Vissers JP, Langridge JI, Aerts JM. Analysis and quantification of diagnostic serum markers and protein signatures for Gaucher disease. Mol Cell Proteomics. 2007;6(5):755-66.

27. Silva JC, Denny R, Dorschel CA, et al. Quantitative proteomic analysis by accurate mass retention time pairs. Anal Chem. 2005; 77(7):2187-200.

28. Kuot A, Hewitt AW, Griggs K, et al. Association of TCF4 and CLU polymorphisms with Fuchs/' endothelial dystrophy and implication of CLU and TGFBI proteins in the disease process. EurJ Hum Genet. 2012;20(6):632-8.

29. Simon P. Q-Gene: processing quantitative real-time RT-PCR data. Bioinformatics. 2003; 19(11):1439-40.

30. Lynn DJ, Winsor GL, Chan C, et al. InnateDB: facilitating systems-level analyses of the mammalian innate immune response. Mol Syst Biol. 2008; 4:218.

31. Weller J M, Zenkel M, Schlötzer-Schrehardt U, Bachmann BO, Tourtas T, Kruse 
FE. Extracellular Matrix Alterations in Late-Onset Fuchs' Corneal Dystrophy. Invest Ophthalmol Vis Sci. 2014;55(6):3700-8.

32. Wieben ED, Aleff RA, Tang $X$, et al. Trinucleotide Repeat Expansion in the Transcription Factor 4 (TCF4) Gene Leads to Widespread mRNA Splicing Changes in Fuchs' Endothelial Corneal Dystrophy. Invest Ophthalmol Vis Sci. 2017;58(1):343-52.

33. Jurkunas UV, Rawe I, Bitar MS, et al. Decreased expression of peroxiredoxins in Fuchs' endothelial dystrophy. Invest Ophthalmol Vis Sci. 2008;49(7):2956-63.

34. Poulsen ET, Dyrlund TF, Runager K, et al. Proteomics of Fuchs' Endothelial Corneal Dystrophy support that the extracellular matrix of Descemet's membrane is disordered. J Proteome Res. 2014.

35. Johnson DH, Bourne WM, Campbell RJ. The Ultrastructure of Descemet's Membrane: I. Changes With Age in Normal Corneas. Arch Ophthalmol. 1982; 100(12): 1942-7.

36. Waring GO, 3rd. Posterior collagenous layer of the cornea. Ultrastructural classification of abnormal collagenous tissue posterior to Descemet's membrane in 30 cases. Arch Ophthalmol. 1982; 100(1):122-34.

37. Bourne WM. Biology of the corneal endothelium in health and disease. Eye. 2003; 17(8): 912-8.

38. Huang Y, Mahley RW. Apolipoprotein E: Structure and Function in Lipid Metabolism, Neurobiology, and Alzheimer's Diseases. Neurobiol Dis. 2014;72PA:312.

39. Tudorache IF, Trusca VG, Gafencu AV. Apolipoprotein E - A Multifunctional Protein with Implications in Various Pathologies as a Result of Its Structural Features. Comput \& struct biotech J. 2017;15:359-65.

40. Niu N, Zhang J, Guo Y, Zhao Y, Korteweg C, Gu J. Expression and distribution of immunoglobulin $G$ and its receptors in the human nervous system. The InternationalJ Biochem \& Cell Biol. 2011;43(4):556-63.

41. Pan B, Zheng S, Liu C, Xu Y. Suppression of IGHGl gene expression by siRNA 
leads to growth inhibition and apoptosis induction in human prostate cancer cell. $\mathrm{Mol}$ Biol Rep. 2013;40(1):27-33.

42. Li X, Ni R, Chen J, et al. The presence of IGHG1 in human pancreatic carcinomas is associated with immune evasion mechanisms. Pancreas. 2011;40(5): 753-61.

43. Qiu Y, Korteweg C, Chen Z, et al. Immunoglobulin $G$ expression and its colocalization with complement proteins in papillary thyroid cancer. Mod Pathol. 2012; 25(1):36-45.

44. Weisgraber KH. Apolipoprotein E: structure-function relationships. Adv Protein Chem. 1994; 45:249-302.

45. Libeu CP, Lund-Katz S, Phillips $M C$, et al. New insights into the heparan sulfate proteoglycan-binding activity of apolipoprotein E. I Biol Chem. 2001;276(42):39138-44.

46. Hui DY, Basford JE. Distinct signaling mechanisms for apoE inhibition of cell migration and proliferation. Neurobiol Aging. 2005;26(3):317-23.

47. Huang DY, Weisgraber $\mathrm{KH}$, Strittmatter WJ, Matthew WD. Interaction of apolipoprotein $\mathrm{E}$ with laminin increases neuronal adhesion and alters neurite morphology. Exp Neurol. 1995; 136(2):251-7.

48. Allan LL, Hoefl K, Zheng DJ, et al. Apolipoprotein-mediated lipid antigen presentation in B cells provides a pathway for innate help by NKT cells. Blood. 2009; 114(12):2411-6.

49. Methia N, André P, Hafezi-Moghadam A, Economopoulos M, Thomas KL, Wagner DD. ApoE deficiency compromises the blood brain barrier especially after injury. Mol Med. 2001;7(12):810-5.

50. Fust A, Csuka D, Imre L, et al. The role of complement activation in the pathogenesis of Fuchs' dystrophy. Mol Immunol. 2014;58(2):177-81. 


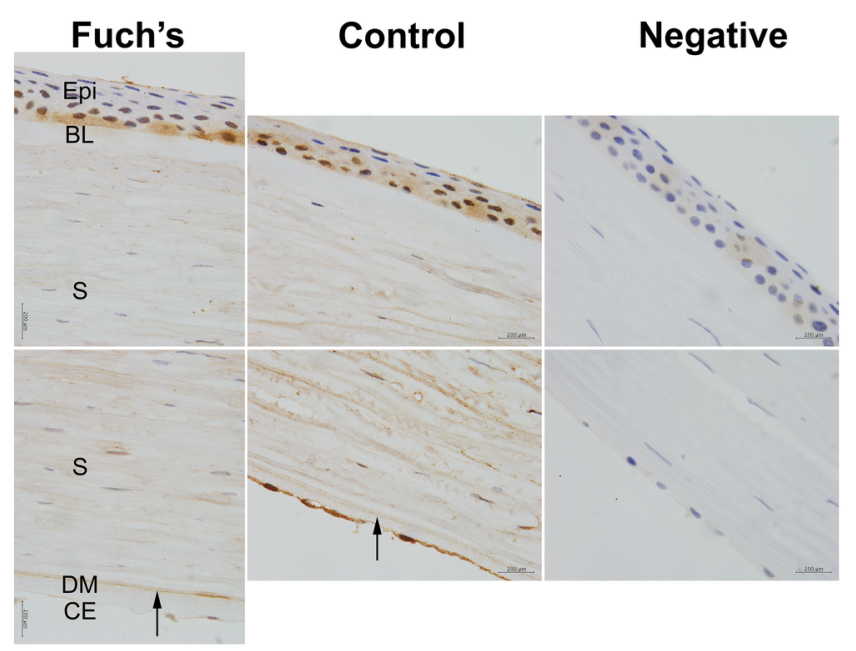

CEO_13569_CEO-19-01-0001 figure 1.tif

This article is protected by copyright. All rights reserved. 


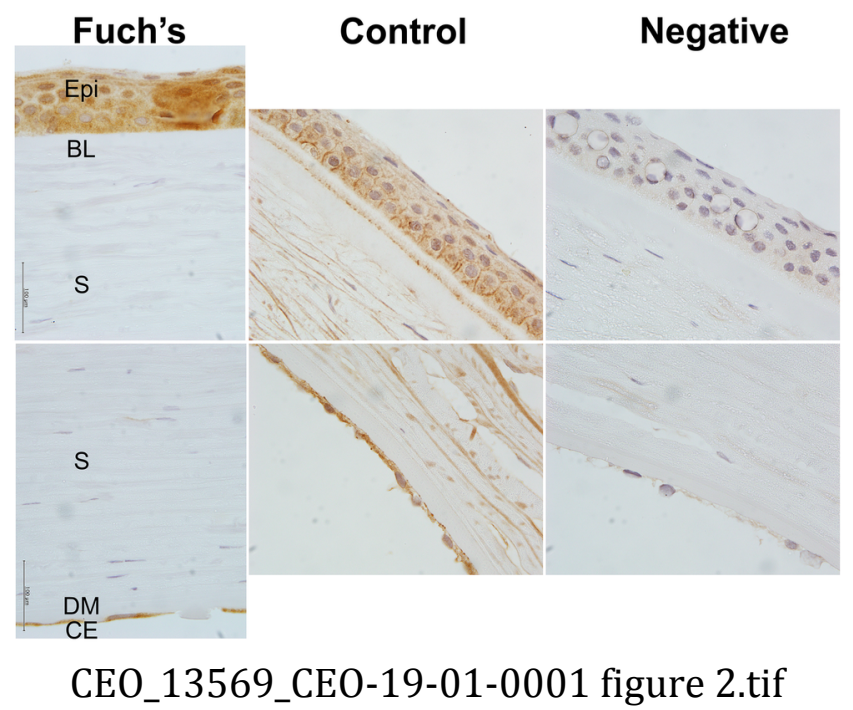

This article is protected by copyright. All rights reserved. 


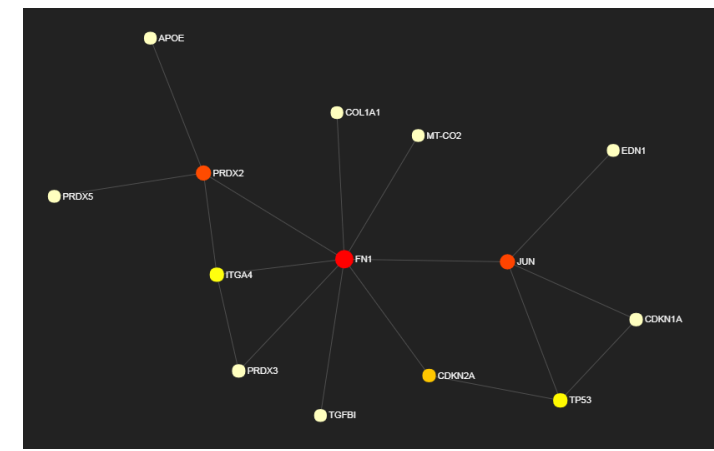

CEO_13569_CE0-19-01-0001 figure 4.tiff

This article is protected by copyright. All rights reserved. 


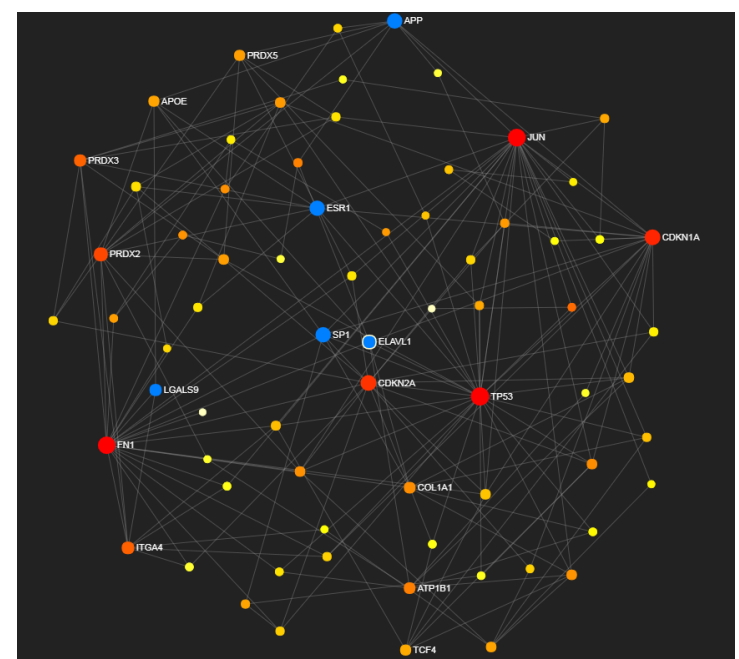

CEO_13569_CE0-19-01-0001 figure 5.tiff

This article is protected by copyright. All rights reserved. 


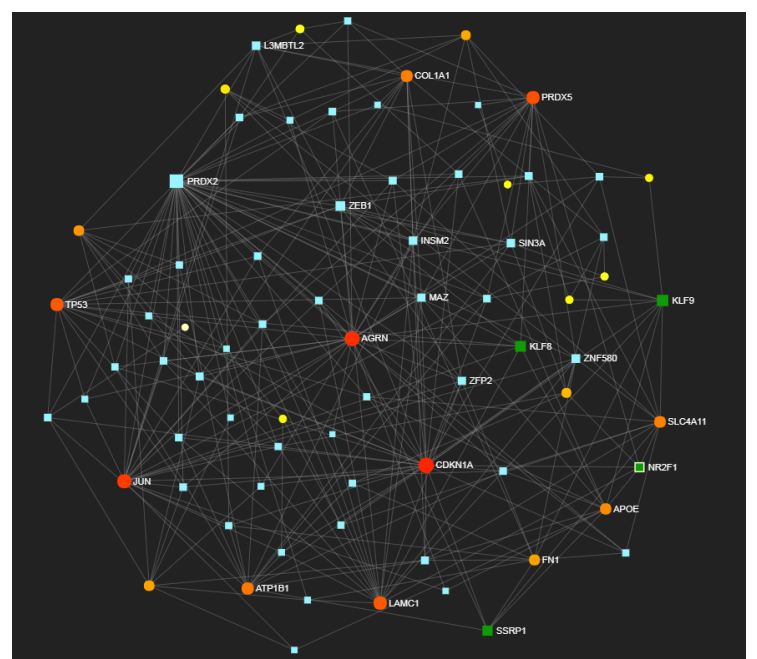

CEO_13569_CE0-19-01-0001 figure 6.tiff

This article is protected by copyright. All rights reserved. 


\section{University Library}

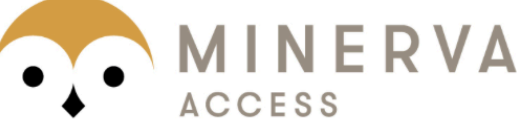

A gateway to Melbourne's research publications

Minerva Access is the Institutional Repository of The University of Melbourne

Author/s:

Kuot, A;Ronci, M;Mills, R;Klebe, S;Snibson, G;Wiffen, S;Loh, R;Corbett, M;Zhou, T;Chataway,

T;Burdon, KP;Craig, JE;Urbani, A;Sharma, S

Title:

Reduced expression of apolipoprotein $\mathrm{E}$ and immunoglobulin heavy constant gamma 1 proteins in Fuchs endothelial corneal dystrophy

Date:

2019-11-01

Citation:

Kuot, A., Ronci, M., Mills, R., Klebe, S., Snibson, G., Wiffen, S., Loh, R., Corbett, M., Zhou, T., Chataway, T., Burdon, K. P., Craig, J. E., Urbani, A. \& Sharma, S. (2019). Reduced expression of apolipoprotein $E$ and immunoglobulin heavy constant gamma 1 proteins in Fuchs endothelial corneal dystrophy. CLINICAL AND EXPERIMENTAL OPHTHALMOLOGY, 47 (8), pp.1028-1042. https://doi.org/10.1111/ceo.13569.

Persistent Link:

http://hdl.handle.net/11343/286121 